\title{
Truancy and injury-related mortality
}

\author{
Amy Bailey, ${ }^{1}$ Gregory R Istre, ${ }^{1}$ Carrie Nie, ${ }^{1}$ Janis Evans, ${ }^{2}$ Reade Quinton, ${ }^{3}$ \\ Shelli Stephens-Stidham ${ }^{1}$
}

${ }^{1}$ Injury Prevention Center of Greater Dallas, Dallas, Texas, USA

${ }^{2}$ Dallas County Juvenile Department, Dallas, Texas, USA

${ }^{3}$ The Southwestern Institute of Forensic Sciences, Office of the Medical Examiner, Dallas, Texas, USA

\section{Correspondence to} Amy Bailey, Injury Prevention Center of Greater Dallas, 6300 Harry Hines Blvd., Suite 240, Dallas, TX 75235, USA; amy.bailey@phhs.org.

Received 15 April 2014 Revised 6 August 2014 Accepted 26 August 2014 Published Online First 10 September 2014

\section{ABSTRACT}

Truancy has well-documented short-term and long-term consequences, but there are few studies that look at its impact on injury-related mortality. This study evaluated the rate of injury-related mortality for 2006-2010 among youth (11-17 years old) with a history of severe truancy compared with youth without such history. There were 168 injury-related deaths (51 homicide, 29 suicide and 88 unintentional injury deaths) among youth in Dallas County. Fifteen of these deaths were among youth with a history of severe truancy. Injury-related mortality was more than five times higher among youth with history of severe truancy compared with youth without such history. Youth with a history of severe truancy have an increased risk of injury-related death. Further research may be warranted to evaluate the part of less severe levels of truancy on mortality and to study the effectiveness of truancy intervention programmes on the risk of death from injuries.

\section{INTRODUCTION}

There are many short-term and long-term consequences of truancy. In the short term, truancy has been associated with alcohol and drug use, ${ }^{1-4}$ stealing, ${ }^{4}$ medically treated injury ${ }^{5}$ and poor academic performance. ${ }^{67}$ In the long term, truancy has consequences that extend into adulthood, including occupational disadvantages and relationship troubles. $^{8}$

Despite these known consequences of truancy, we could find few, if any, studies that examined the mortality consequences of truancy. We used Dallas County Child Death Review Team (CDRT) data to calculate the rates of injury-related mortality among youth 11-17 years of age with and without a history of severe truancy. We expected that those with a history of severe truancy would have a higher rate of injury-related mortality.

\section{METHODS}

\section{Definitions}

For purposes of this analysis, a youth was defined as a person 11-17 years of age for all numerator, denominator and rate calculations.

Contempt of Court for Truancy was defined as a truant youth who missed school after appearing before a judge for truancy, or a truant youth who did not participate in court-ordered community service or programme as ordered by the Judge or Justice of the Peace. We used contempt of court for truancy in this study because accurate counts of denominators were available to us, which allowed calculation of rates. Severe truancy, for this study, was used interchangeably with contempt of court for truancy.

\section{Data}

The study period for this analysis was 1 January 2006 to 31 December 2010. The Dallas County CDRT acquired information from a review of medical examiner reports, team meetings and death certificates. The CDRT reviews all injury-related deaths among children $<18$ years of age for which the incident occurred in Dallas County. Included in this study were all youth who died due to injury (homicide, suicide or unintentional injury) during the study period. The names of youth who fit these criteria were cross-referenced by a CDRT member (JE) at the Dallas County Juvenile Justice Department who identified whether each youth who died due to injury had a history of severe truancy during the study period. For each deceased youth with a history of severe truancy, the date of first entry into the juvenile system during the study period was recorded. Prior to analysis, all personal identifiers were removed from the database.

Numerator data for rate calculations were composed of injury-related deaths during the study period among youth who were identified through the CDRT and classified by history of severe truancy. The denominator for youth with a history of severe truancy, by age and year, was obtained from the Dallas County Juvenile Department. Dallas County population data for youth 11-17 years of age was obtained from the Texas State Data Center for the study period. To estimate the denominator for each year during the study period for youth who did not have a history of severe truancy, we subtracted the number of youth with such a history from the total population estimates for Dallas County for youth (eg, \# youth without history of severe truancy $=\#$ youth total population -\# youth with history of severe truancy).

\section{Statistical analysis}

Rates were calculated as number of injury-related deaths per 100000 person-years of follow-up. A rate was calculated for youth with history of severe truancy and for youth without such history. $\mathrm{RR}$ of death was expressed as an incidence density ratio (eg, $\mathrm{RR}=$ mortality rate for youth with history of severe truancy/mortality rate for youth without history of severe truancy). Comparisons of RR of death were calculated with a conditional maximum likelihood estimate of the RR with exact confidence limits.

Cumulative incidence rates were calculated for those with a history of severe truancy. For numerator data for youth who died with a history of severe truancy, we calculated duration of follow-up as the difference in months between the first offense in the juvenile justice system and death. For numerator data for youth who died without history
To cite: Bailey A, Istre GR, Nie C, et al. Inj Prev 2015;21:57-59. 
Table 1 Injury-related mortality rate* for youth with and without history of severe truancy Dallas County, Texas, USA, 11-17 years of age, 2006-2010

\begin{tabular}{|c|c|c|c|c|c|c|c|}
\hline & $\begin{array}{l}\text { Number of } \\
\text { injury deaths } \\
\text { with history }\end{array}$ & $\begin{array}{l}\text { Person-years } \\
\text { with history }\end{array}$ & $\begin{array}{l}\text { Mortality rate* with } \\
\text { history }(95 \% \mathrm{Cl})\end{array}$ & $\begin{array}{l}\text { Number of } \\
\text { injury deaths } \\
\text { without history }\end{array}$ & $\begin{array}{l}\text { Person-years } \\
\text { without history }\end{array}$ & $\begin{array}{l}\text { Mortality rate* } \\
\text { without history } \\
(95 \% \mathrm{CI})\end{array}$ & $\operatorname{RR}(95 \% \mathrm{Cl})$ \\
\hline Homicide & 8 & 20536 & 39.0 (12.0 to 65.9$)$ & 43 & 1132116 & $3.8(2.7$ to 5.0$)$ & 10.3 (4.5 to 21.0$)$ \\
\hline Suicide & 2 & 20536 & 9.7 (0.0 to 23.2$)$ & 27 & 1132116 & 2.4 (1.4 to 3.3 ) & $4.1(0.7$ to 14.6$)$ \\
\hline Unintentional & 5 & 20536 & 24.4 (3.0 to 45.7 ) & 83 & 1132116 & 7.3 (5.8 to 8.9 ) & 3.3 (1.2 to 7.6$)$ \\
\hline All injury & 15 & 20536 & 73.0 (36.1 to 110.0$)$ & 153 & 1132116 & 13.5 (11.4 to 15.7$)$ & $5.4(3.1$ to 9.0$)$ \\
\hline
\end{tabular}

of severe truancy, we calculated duration of follow-up as the difference in months between first eligibility for follow-up (the beginning of the study period or when the youth turned 11 years old) and death. Denominator data for severe truants and non-truants was calculated by determining the number of months eligible for follow-up during the study period after turning 11 years of age and until turning 18 years of age. For the non-truant denominator, we assumed that $1 / 12$ of the 17-year-old population turned 18 years of age each month and adjusted the estimate for the 17 -year-old population accordingly. We calculated cumulative incidence as 1 minus the survival probability. The Kolmogorov-Smirnov equality of distributions test was conducted for comparison of cumulative mortality rates.

Data were analysed with Epi Info ${ }^{\mathrm{TM}}$ 3.5.3 (CDC, Atlanta, Georgia, USA) and STATA V.9.0 (STATA, College Station, Texas, USA). This study was deemed to have exempt status by the University of Texas Southwestern Medical Center Institutional Review Board.

\section{RESULTS}

Between 2006 and 2010, the average annual number of truant youth in Dallas County was 1881 and the average annual number of non-truant youth was 239627 . In Dallas County between 2006 and 2010, there were 168 injury-related deaths (51 homicide, 29 suicide and 88 unintentional injury deaths) among youths 11-17 years of age. Among those 168 deceased youth, $15(8.9 \%)$ youth had a history of severe truancy.
Injury-related mortality rate was 73.0 per 100000 personyears among youth with history of severe truancy compared with 13.5 per 100000 person-years among youth without such a history (RR, 5.4, 95\% CI 3.1 to 9.0, p<0.01). RR for those with a history of severe truancy was highest for deaths due to homicide (RR, 10.3, 95\% CI 4.5 to $21.0, \mathrm{p}<0.01$ ), followed by suicide (RR, 4.1, 95\% CI 0.7 to $14.6, p=0.11$ ) and unintentional injury (RR, 3.3, 95\% CI 1.2 to $7.6 \mathrm{p}<0.03$ ). (table 1 ).

\section{Cumulative mortality rate}

The cumulative mortality rate for youth with and without history of severe truancy is shown in figure 1. There was a significant difference between those with a history of severe truancy and those without $(\mathrm{p}<0.001$ by Kolmogorov-Smirnov equality of distributions test). The highest mortality rates occurred in the first 3 years after the offense for severely truant youth.

\section{DISCUSSION}

We found that youth with a history of severe truancy had an elevated risk of injury-related mortality. Homicide had the greatest RR for severe truants, followed by suicide and unintentional injuries. Previous studies have found truancy to be a risk factor for short-term risk behaviours ${ }^{1-7}$ and for longer-term consequences. ${ }^{8}$ However, we could find only one previous study which reported that youth who died due to homicide had a history of truancy as well as other social issues, but the risks were not quantified. ${ }^{9}$ We found no studies which reported that
Figure 1 Comparison of cumulative mortality rates between youth with or without history of severe truancy, by months of follow-up, Dallas County, 2006-2010.
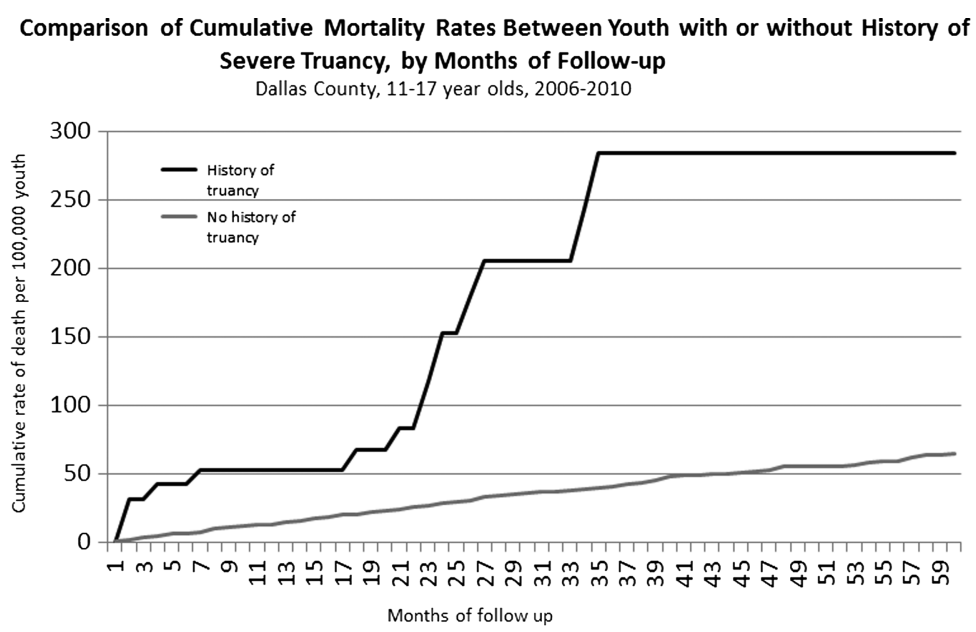

\begin{tabular}{lcccccc} 
No. Persons at Risk & $\mathbf{0}$ years & $\mathbf{1}$ year & 2 years & 3 years & 4 years & 5 years \\
History of truancy & 9405 & 9266 & 5651 & 2325 & 664 & 86 \\
No history of truancy & 365175 & 339886 & 277338 & 213559 & 147572 & 79458 \\
\hline
\end{tabular}


truant youth were at elevated risk of death due to suicide or unintentional injuries.

There are several limitations to this study. First, for youth who died, we did not include the case in the truancy numerator if all offenses occurred before 2006, which may have underestimated truancy-related mortality rates. Additionally, the CDRT did not identify deaths among youth after the age of 17 years. This may have led to an underestimation of mortality due to the fact that some youth who were truant before age 18 years may have died of an injury after that age, and would not have been included in either numerator for rate calculations. Furthermore, we did not have access to data on less severe truancy, such as truancy that did not escalate to the level of contempt of court for truancy; thus, we could not calculate the impact of less severe truancy on risk of injury-related death. Additionally, we could not identify whether youth who died in Dallas County had a history of truancy elsewhere or if youth who were counted in the population of Dallas County died elsewhere. None of the youth who met the definition for severe truancy were out-of-county residents. Finally, the association between early mortality risk and truancy is likely due to a complex set of factors, including drug use, fighting, antisocial behaviour, and so

\section{What is already known on the subject}

Truancy is a risk factor for short-term and long-term risk-taking behaviour.

\section{What this study adds}

- Mortality among youth who have a history of severe truancy is five times higher than those without such history.

- This mortality risk is highest among severe truants in the first 3 years after entry into the juvenile justice system. on, for which truancy is a marker, rather than a cause. We could not separate those other factors in the calculations.

It appears from our local data that youth with severe truancy have the highest risk of injury-related death in the first 3 years after their recorded offense in the juvenile system. Since truancy appears to be a marker for risk of death, identification and intervention before youth meet this high-risk criterion has the potential to decrease risk of injury-related death. Further research is warranted to evaluate effectiveness of truancy intervention programmes on the risk of death from injuries.

Acknowledgements We are indebted to the Dallas County Child Death Review Team, without whose assistance this project could not have been done.

Contributors $A B, C N, J E, R Q, S S-S$ and $G I$ contributed to the concept and design of the project. JE, RQ, $A B$ and $C N$ contributed to the collection the data. $A B$ and GRI collaborated on the analyses, interpreting the results and writing the article. CN and SS provided administrative support for the project. AB and GRI had access to all data and are responsible for the overall content. All authors reviewed and approved the final version.

\section{Competing interests None.}

Ethics approval IRB exempt.

Provenance and peer review Not commissioned; externally peer reviewed.

\section{REFERENCES}

1 Brown TN, Schulenberg J, Bachman JG, et al. Are risk and protective factors for substance use consistent across historical time: national data from the high school classes of 1976 through 1999. Prev Sci 2001;2:29-43.

2 Hallfors D, Vevea JL, Irtani B. Truancy, grade point average and sexual activity: A meta-analysis of risk indicators for youth substance use. J Sch Health 2002;72:205-11.

3 Chou L, Ho C, Chen C, et al. Truancy and illicit drug use among adolescents surveyed via street outreach. Addict Behav 2006;31:149-54.

4 Vaughn MG, Maynard BR, Salas-Wright CP, et al. Prevalence and correlates of truancy in the US: Results form a national sample. J Adolesc 2013;36:767-76.

5 Buckley L, Chapman R, Sheehan M. Adolescent involvement in anti-social and delinquent behaviours: Predicting future injury risk. Accid Anal Prev 2012;48:518-22.

6 Siziya S, Muula AS, Rudatsikira E. Prevalence and correlates of truancy in Swaziland: findings from the Global School-Based Health Survey. Child Adolesc Psychiatry Ment Health 2007;1:15.

7 Hunt MK, Hopko DR. Predicting high school truancy among students in the Appalachian South. J Prim Prev 2009;30:549-67.

8 Hibbett A, Fogelman K. Future lives of truants: Family formation and health-related behavior. Br J Educ Psychol 1990;60:171-9.

9 Onwuachi-Saunders $C$, Forjuoh SN, West $P$, et al. Child death reviews: a gold mine for injury prevention and control. Inj Prev 1999;5:276-9.

\section{Canada muzzles scientists}

I recently made reference to an editorial I wrote for a Canadian journal that included two sentences the editor removed because he judged the government would not approve. Those sentences suggested Health Canada could and should do more to prevent injuries. This is not an isolated event. The Montreal Gazette reported 'over 800 scientists from around the world have signed an open letter to Prime Minister Harper decrying what they call a rapid decline in funding and freedoms faced by Canadian Government scientists.' 